\title{
CALIDAD DE VIDA
}

\author{
QUALITY OF LIFE
}

\section{LUIS BORTESI LONGHI ${ }^{*}$}

Docente Asociado de la Facultad de Ciencias Contables - UNMSM

[Recepción: Febrero de 2011/ Conformidad: Abril de 2011]

\section{RESUMEN}

El tema de la calidad de vida encierra el propósito central y natural que toda persona persigue a veces de manera instintiva y en algunos otros casos con conciencia lúcida e igualmente ocurre con la sociedad entera donde se proponen objetivos y metas para vivir mejor. Los gobiernos, por su parte, también tienen como objetivo final o a ultranza el propósito de lograr "el bienestar general" para sus pueblos, pero en este contexto se impone una reflexión previa, vale decir premisa, para examinar con detenimiento un concepto tan importante y tan trascendente cual es el verdadero contenido y la dimensión de la calidad de vida.

Evidentemente no todos los factores que concurren en la determinación del nivel de satisfacción son materiales sino que por el contrario, aunque la progresiva materialización del mundo moderno y su tecnología parezcan ignorarlo, los principales componentes de la calidad de vida, cualitativos por definición, no derivan del caudal de los ingresos económicos o de la cantidad del consumo puesto que vivir mejor implica exigencias y cultivo de virtudes que trascienden el reino de la cantidad.

Palabras Clave: cantidad - calidad - salud - paz

\begin{abstract}
The issue of quality of life contains the core purpose and natural that everyone pursues instinctively sometimes and in some other cases with clear consciousness and so does the whole society which proposes objectives and goals for better living. Governments, meanwhile, also have final objective or the purpose of achieving uncompromising "general welfare" for their people, but in this context requires a previous reflection, that is premised, to examine in detail such an important concept and so important what the real content and dimension about quality of life. Obviously not all the factors that concur in determining the level of satisfaction are material but on the contrary, although the progressive realization of the modern world and technology seem to ignore it, the main components of quality of life, qualitative by definition, not derived flow of income or the amount consumed as live better means growing demands and virtues that transcend the realm of quantity.
\end{abstract}

Key words: quantity - quality - health peace

\footnotetext{
* Doctor en Ciencias Económicas- PUCP, Magister en Ciencias Económicas- PUCP, Docente Investigador de la Facultad de Ciencias Contables - UNMSM.

E- mail: luisbortesil@hotmail.com
} 


\section{INTRODUCCIÓN}

El bienestar general es un concepto relativamente abstracto que difiere sustancialmente entre las escuelas y sus doctrinas. El socialismo, la socialdemocracia cristiana y el liberalismo, por ejemplo, no coinciden al explicar el contenido y las estrategias para dispensar el bienestar de los pueblos. En algunos casos extremos incluso se prioriza el gasto militar bajo el eufemismo de "defensa" entendiendo que el poderío bélico ocupa el primer lugar.

El propósito del presente escrito es analizar los principales factores que intervienen en la determinación del nivel de la calidad de vida y tratar de demostrar que ésta no es paralela ni directamente proporcional a los índices económicos, como por ejemplo la renta per cápita, puesto que aún disfrutando de un ingreso económico alto si se sufre de estrés, o sea de angustia, el dinero sólo sirve para comprar fármacos y estupefacientes. $\mathrm{Y}$ a este propósito se puede comentar que, desgraciadamente, muchos países que tienen altos per cápita también tienen altos índices de suicidio. Claro está que un nivel de ingreso miserable no va a contribuir al nivel de vida puesto que resulta ser tan indeseable como su contraria, es decir, la saturación provocada por el dinero. La mayoría de la gente que posee grandes fortunas vive en tensión ya sea por el afán de acumular más, lo que constituye una manía, una especie de locura, o porque lo atormenta el miedo de perderla. Pero eso no es todo con respecto a las desventajas que acarrean las grandes fortunas: muchos jóvenes famosos, deportistas por ejemplo, millonarios de la noche a la mañana, se arruinan en la calidad de vida porque por falta de formación intelectual se descarrilan víctimas de drogas, pornografía y todo tipo de vene- nos. Para ellos el golpe de fortuna se convierte en una verdadera maldición.

La tecnología moderna nos ofrece muchos nuevos inventos y productos para aumentar el confort y también para hacer las cosas con mayor velocidad pero hay que reconocer que puede tener la tecnología moderna su aspecto negativo y que puede contribuir a idiotizar, como que de hecho la humanidad parece retroceder con un embrutecimiento progresivo si se piensa en que cada vez somos más automáticos en nuestros estados de conciencia. La televisión, los juegos mecánicos, los casinos, el chateo, son pruebas contundentes.

Conviene refrescar el concepto de cultura y revisar los verdaderos alcances de la tan presumida y vanagloriada "era del conocimiento". Porque la verdad es que si se reemplaza la abstracción y el cultivo de los valores como son el bien, la verdad, la belleza, la justicia y la paz interior, por el culto a las imágenes y se abandona la introversión por el divertimiento, la dirección en la que discurre la humanidad es inferior. En efecto, la "diversión", literalmente hablando. consiste en proyectar la conciencia hacia el exterior y en consecuencia su resultado es exactamente contrario a la vitalidad interior que se experimenta en las profundidades de la meditación donde se desarrolla íntimamente la verdadera lucidez. La era del conocimiento tiene prestigio a raíz de la democratización de la información y es éste un hecho indiscutible, pero hay que acotar que hay una gran diferencia entre información y conocimiento. La información es de carácter general, vulgar, no selectiva y muchas veces caótica. El conocimiento es otra cosa. La información tiene que ver con los datos y las estadísticas y con el acervo de registros, el conocimiento tiene que ver con la sabiduría. 


\section{FACTORES QUE CONCURREN EN LA CALIDAD DE VIDA}

Empecemos por el entorno social y el paisaje que nos rodea. Un paisaje agradable gratifica la existencia así como la música, la frescura y los perfumes, el cielo, los árboles, las flores, transmiten alegría sensorial y estimulan el equilibrio fortaleciendo el estado de conciencia. Con respecto al entorno social (que en cierta manera es paralelo al paisaje) tenemos al prójimo por ejemplo en el tránsito vehicular. Si todos los conductores tuvieran la educación, la cultura y la paciencia necesaria para respetarse mutuamente la calidad de vida sería superior y en este sentido es pertinente mencionar que este es uno de los factores del desarrollo social que no es un derivado directo del desarrollo económico, dicho de otra manera, una colectividad puede vivir mejor si existe respeto por los demás aunque no tenga altísimas tasas de producción y consumo. Por supuesto que el tema del entorno social se verifica también con los vecinos, en el barrio y en el ambiente de trabajo. Los ruidos molestos y la falta de respeto por la vecindad y las famosas vulgares y ruidosas "jaranas" desenfrenadas en la madrugada son un atentado que deprime la calidad de vida y rompe los nervios.

En el entorno relacionado con el ambiente de trabajo un asunto que conspira contra la calidad de vida es la prisa, costumbre tan generalizada en nuestros tiempos, y se presume que es una virtud, mientras que es una enfermedad, una forma de neurosis colectiva y contagiosa. Cuando el jefe frenético te dice que la tarea es “ipara ayer!” como si lo diera por sobreentendido, comete un error porque casi siempre los trabajos hechos con desesperación salen mal y hay que repetirlos. Lo paradójico de la prisa es que una buena mayoría de los inventos modernos deben servir para ganar tiempo y para acortar distancias, sin embargo cada vez el tiempo resulta un recurso más escaso a tal extremo que se ha popularizado la expresión "el tiempo vale más que el dinero". Un infausto cómplice del caos que produce la prisa es el telefonito celular, ese intruso que interrumpe las reuniones y las ocasiones más íntimas. Una manía paralela, prima hermana de la prisa, es la triste costumbre "fast food", heredada de la primera potencia del mundo (pero no en materia cultural) y se almuerza sin dignidad y sin ni siquiera lavarse las manos. $\mathrm{Y}$ a propósito de la alimentación, bueno es reconocer que su participación en la calidad de vida no deriva del comer más, sino del comer mejor, debiéndose señalar a este respecto que la mejor alimentación no es necesariamente directamente proporcional al presupuesto invertido. Una prueba que se puede adjuntar para demostrar lo dicho es que la obesidad es una desgracia generalizada con mayor frecuencia en los países ricos y afecta no solamente a gente mayor sino también a jóvenes y a niños. La calidad del sueño está vinculada a la alimentación y una comprobación de que se duerme bien es que se experimente con frescura y placidez.

Las necesidades y su satisfacción son un aspecto fundamental obvio en la calidad de vida, sin embargo en este punto se impone una observación importante que se puede formular con la siguiente pregunta: ¿quién vive mejor, aquel que está oprimido por un sinfín de necesidades o en cambio el que tiene pocas exigencias? Por eso el consumismo pese a ser tan criticado marca una voracidad, estimulada por el marketing, de aceleración creciente y este es un defecto que a la larga deprime la calidad de vida. Dos enemigos que se presentan para producir necesidades artificialmente son la moda y la envidia. "Estar a la moda" es un deseo insaciable de gente 
generalmente superficial que la hace desdichada y la envidia consiste en el afán absurdo de querer tener lo que se ha visto del vecino aunque en el fondo el asunto no revista mayor trascendencia. Se necesita dinero entonces para implantarse tatuajes, poseer collares de oro como dogales, relojes ostentosos y todas las cosas de ese género. Un coche nuevo, un vestido de seda, un nuevo par de anteojos de sol (para ajustarlos encima del cráneo "a la moda” ), una piscina de mármol.... El ego desmesurado tarde o temprano rebotará en contra del pretendiente fatuo, superficial y absurdo. La autoestima es aconsejable dentro de los parámetros de la realidad pero la soberbia y la estupidez humana a la larga cobran su precio.

Las necesidades básicas como son la alimentación, el abrigo y el techo requieren para su satisfacción un ingreso económico razonable que permita holgura puesto que de lo contrario es evidente que el yugo de la carestía deprimirá el nivel de vida. Reconocido esto, la necesidad que ocupa la primera prioridad es la de la educación en el sentido que una adecuada formación integral constituye un factor clave que permitirá el desarrollo y la realización personal a lo largo de la vida y en este sentido la definición previa está dada por encontrar, desde la adolescencia, la inspiración profunda que proviene de la vocación de suerte que la persona cobra autoestima y dignidad, dotes que perfilan un buen pronóstico en lo que concierne a la calidad de vida.

Para concluir con este párrafo de las necesidades podemos señalar que, sin perjuicio de lo señalado líneas arriba, algunas de las más imperativas, como el afecto o la necesidad de pertenencia, no dependen del nivel económico sino que le son ajenas.

La vocación y el trabajo creativo son factores de suma importancia en la vida humana y conviene analizar este tema con de- tenimiento. Ante todo hay que decir que son muy escasas las personas que tienen el privilegio de descubrir ese secreto tesoro interior que es la vocación y hay que decir, además, que una persona puede tener varias vocaciones en la medida en que tenga facultades de imaginación y riqueza interior. Pero lo cierto es que si un joven descubre su verdadera vocación y le es fiel, con prescindencia de consideraciones prácticas en el mercado laboral, tiene mucho más oportunidad de labrarse una vida satisfactoria y viceversa, si ese joven escoge profesión o actividad impulsado exclusivamente por el sentido práctico lo más probable es que aún alcanzando el "éxito" su trabajo le resulte agobiante, penoso y un verdadero calvario. En cambio aquel que trabaja en lo que le gusta puede terminar la jornada con una fatiga natural pero estará siempre con un mejor estado de ánimo.

Insistiendo con el tema del trabajo, si éste no es creativo, deprime el estado de conciencia de la persona y tiende a robotizarla determinando en consecuencia un nivel de vida parecido al de una máquina. Muchas personas creen que al hablar de trabajo creativo hay que referirse exclusivamente al arte y eso no es del todo cierto. Es verdad que en el desempeño artístico intervienen la imaginación y la creación pura, sin embargo otro tipo de trabajos y actividades también tienen una faceta "artística" y creativa. Por ejemplo un jardinero, por modesta que sea su profesión, si hace su trabajo con vocación e imaginación tiene la remuneración y la satisfacción que proporciona el trabajo creativo. Lo mismo se puede decir de un sastre, de un cocinero. Pero desgraciadamente la tecnología y la realidad del mundo contemporáneo nos hacen comprobar que no son muchos los trabajos verdaderamente creativos y que la rutina es el peor enemigo en el quehacer diario. Un obrero que trabaja, al servicio de la máqui- 
na, ensamblando piezas o un chofer de combi, están condenados a un nivel deprimido y deshumanizado en el nivel de vida y a este respecto tal vez el caso más patético sea el del ascensorista.

Hay tres personajes históricos y descollantes en la teoría y en la sistematización del trabajo organizado en serie y en masa: los norteamericanos Henry Ford; F. W. Taylor y el francés Henri Fayol.

Frederick Winslow Taylor el "precursor de la productividad", reputado como el "Padre de la Administración Científica”, en su libro "Principios de la Administración Científica” (The Principles of Scientific Management - Harper and Row - Publishers - New York) dice textualmente en la página 44:

"Ahora bien, una de las primeras cualidades que debe poseer un obrero que quiera transportar lingotes de hierro, una ocupación regular, es que sea tan torpe y tan flemático que se parezca en su contextura mental más a un buey que a cualquier otra cosa. El obrero de mentalidad viva e inteligente es por ésta misma razón completamente inapropiado..."

\section{¡SIN COMENTARIOS! ¡NO COM- MENT! (Mr. Taylor)}

La importancia del ocio es el factor que se estudia a continuación, aclarándose de antemano que obviamente no nos estamos refiriendo a la holgazanería como vicio y pecado capital que es la pereza sino a la capacidad recreativa en el sentido literal de "crear de nuevo" y que tiene tanto o más importancia que el trabajo obligatorio. Romper la rutina y aprovechar los tiempos libres de manera útil, constructiva y placentera juega un papel determinante en el nivel de la calidad de vida. Hay gente que tiene adicción al trabajo y no es capaz ni sabe hacer otra cosa que deslomarse trabajando y consagrarse apasionadamente a los negocios (y lo curioso e interesante es que la palabra "negocio" significa literalmente "negación del ocio") y en este caso se configura un defecto semejante a otras adicciones tales como la ludopatía o la gula. Una anotación trascendente se debe remarcar y esta es que incluso desde el punto de vista de la Doctrina está presente un mandamiento superior que es "Santificar las Fiestas”, precepto que ocupa el tercer lugar jerárquico en el Decálogo y el profundo significado del ocio creativo radica en el desarrollo de la paz interior o sea del cultivo del espíritu. Un buen ejemplo sencillo sobre esta aserción es la contemplación grata y serena de un crepúsculo.

Muchos de los inventos y descubrimientos que han impulsado al mundo han tenido lugar al margen de la rutina del horario de trabajo y los recuerdos más gratificantes de nuestra existencia ubican episodios vividos gracias al usufructo del tiempo libre: un día en el campo, un día en la playa, un beso, un sueño, una lectura, un viaje inolvidable.

Para los jóvenes un espacio de tiempo libre indispensable es el que deben aplicar al deporte porque bien claro está que el ejercicio deportivo es un antídoto natural contra el alcohol y las drogas y por supuesto un elemento de vitalidad y de salud.

El mayor bien es pequeño si se compara con la fortuna de gozar de buena salud pero este factor básico merece ser analizado en su totalidad porque no es frecuente encontrar personas plenamente saludables. Lo más frecuente es que rutinariamente cada cierto tiempo la persona se someta al consabido "chequeo médico" mediante el cual obtiene los indicadores objetivos, los parámetros de su estado físico y probablemente, satisfecho, declare entre sus amigos que está "en plena forma" ya que el doctor le dijo "tiene usted la salud de un joven deportista de 20 años, 
lo felicito". Pero eso, aún siendo una buena noticia, no es suficiente, porque intervienen en el nivel óptimo de salud otros ingredientes más sutiles que corresponden al terreno del alma. Si sufre el flagelo de la envidia, de la cólera, del estrés, de los celos y del odio, el famoso chequeo médico ha sido un verdadero fiasco.

Se dice, para empezar, que es un factor básico porque sin él ningún otro cuenta. En el rito consuetudinario de nuestro trato con el prójimo el "saludo" debe ser un acto de la voluntad para impartirle o desearle salud al otro, eso significa saludar aunque tal vez muchos no sean conscientes de esta etimología.

Hay que hacer una precisión con respecto al concepto de lo que se considera "normal”, para aclarar que está divulgado el criterio según el cual la normalidad está dada por aquello que hace la mayoría o que representa la mayoría. Grave error de apreciación puesto que si la enorme mayoría está mal (como que lo está) eso no se puede calificar de normal. Lo normal es que la mayoría de los jóvenes americanos consuman marihuana, según la estadística, pero la verdadera normalidad no responde a las cifras cuantitativas sino a aquello que debe dictar la "norma”. Otro buen ejemplo a este respecto es precisamente el de la salud donde la gente supone que está sana pero que no lo está porque si sufre de estrés, como la mayoría, no lo está y tampoco lo está si tiene impulsos de odio o de envidia. El criterio para calificar la normalidad no puede ser cuantitativo sino cualitativo y selectivo.

Sentirse bien de manera integral es sin duda el exponente que sintetiza la calidad de vida, sin embargo, eso no implica solamente no padecer ninguna enfermedad física sino un equilibrio psicosomático que incluye en prioridad el alma y el espíritu de manera tal que la persona no está oprimida por ningún tipo de malestar, pero lograr ese estado semi beatífico en una megalópolis es prácticamente imposible. La inseguridad, la contaminación, la polución sonora, la agresividad y la tensión que afecta la existencia en las ciudades muy pobladas son rasgos incontestables que con frecuencia determinan que la vida se torne cuasi "invivible". Pero al margen de esta acotación extrema hay otras circunstancias más particulares que afectan la salud integral como por ejemplo la precariedad de las instituciones que equivale a una inestabilidad continua donde se postula que "lo único permanente es el cambio", situación que decreta inexorablemente la angustia ya sea por perder el trabajo o por el temor de que se dé un cambio brusco en la política o en cualquier otro escenario donde se desarrolla nuestra vida. La mayoría de las personas en consecuencia no están totalmente sanas aunque aparenten estarlo porque sufren insomnio, a veces paranoia o manía persecutoria, ludopatía, adicciones, envidias y no pocos tienen, en diferente grado, el defecto de ser hipocondriacos.

El sentido del humor es un ingrediente que no deja de tener importancia en la calidad de vida y, aunque tal vez muchos no lo crean, es una facultad humana muy rara porque lo más generalizado es el impulso a la burla y al sarcasmo, cualidad que no tiene nada que ver con el sentido del humor, sino que antes bien se le opone. La mayoría de los programas de la televisión abierta que prometen un rato de humor son en la práctica una estafa que contribuye a la larga a la decepción, a la vulgaridad, a la mediocridad y desmoralizan.

La característica del humor se inscribe en el orden cultural, es un fruto de la cultura que significa cultivo de valores abstractos que forman parte de la inteligencia y la nutren. La diferencia que existe entre la mofa, la burla y el sarcasmo con la inteligencia humorística radica en que la primera se realiza a costa de 
la tortura de alguien al que se enfoca como el punto que va a recibir los dardos del burlón y se convierte en la víctima porque los que entran en estado eufórico lo logran a costa del que sufre. En cambio el ejercicio del humor como fruto cultural lleva como consecuencia que todos experimentan alegría superando aunque fuese transitoriamente los temores y los sinsabores de la existencia. Por lo tanto el sarcasmo es agresivo y participa de la naturaleza de la violencia en tanto que el humor elegante es pacífico y no violento. Es oportuno señalar que las personas agresivas lo suelen ser por razón de su inseguridad y por el miedo a sufrir y es entonces esa tensión la que se proyecta y se descarga al exterior. Dicho en otras palabras, las personas que tienen seguridad en sí mismas, aplomo y sentido del humor, generalmente no son agresivas. Prosiguiendo con esta reflexión alrededor de lo que es violento y de lo que no lo es, se puede señalar una semejanza con la diferencia que se advierte entre erotismo y pornografía, donde lo primero resulta agradable y edificante (Eros es un dios primordial griego) y lo segundo es sencillamente grotesco, sórdido y denigrante. Así también constatamos un paralelo entre la música eufónica, dulce al oído, contra el estruendo bullicioso de las percusiones sonoras que destrozan los tímpanos.

Contar buenos chistes y hacer buenas bromas es una destreza que poseen unos pocos privilegiados dado que en la mayoría de las ocasiones alguien se aventura a contar un chiste que ya todos conocían y para fingir la risa hay que hacerse cosquillas en las axilas. Sin embargo las rondas de chistes, cuando son buenos y bien narrados, contribuyen definitivamente a exaltar el estado de ánimo y por lo tanto a la calidad de vida, aunque es muy poco frecuente que los chistes estén exentos de un matiz obsceno.
Los caricaturistas, artistas eximios de las artes gráficas, suelen ser unos excelentes mensajeros del sentido del humor y afortunadamente los hay muy buenos. En el caso de las caricaturas no se suele ofender al caricaturizado porque se remarcan y exageran los rasgos más simpáticos que posee la persona. En este sentido hay que decir que una característica indubitable del buen sentido del humor es la de tener la capacidad de reírse de sí mismo, porque todos incurrimos eventualmente en el ridículo y eso no menoscaba nuestra dignidad. Por el contrario, quien tiene la capacidad de reírse de sí mismo lo que demuestra es una superioridad de tolerancia y flexibilidad, de amplitud de criterio, todo lo contrario a las limitaciones que sufre una persona acomplejada. En nuestro entorno con toda seguridad hay personas que nunca ríen y eso es una mala señal puesto que esa gente adusta y con el ceño fruncido siempre, tiene una menor capacidad de disfrute porque carece de la facultad mágica de sentido del humor.

La producción cinematográfica de películas cómicas ha mermado considerablemente y al parecer casi se ha extinguido. La industria cinematográfica demuestra su portentoso avance en materia tecnológica y de sonido y en lo que se llama efectos especiales y es así que podemos ver un film extraordinario como la Guerra de las Galaxias o las aventuras de Harry Potter, buenas películas de suspenso, de acción, aunque la mayoría de las entregas contemporáneas contiene un altísimo grado de violencia y de espectaculares desastres. Por eso la mayoría de lo filmado en la actualidad corresponde al género "Drama" lo que quiere decir, en pocas palabras, "tensión" y "sufrimiento". En cambio las películas que tienen como su motivo central el humor hace un buen tiempo que ya no se producen, si recordamos algunas, por citar por ejemplo 
las celebérrimas obras llevadas a la pantalla con la genialidad de Chaplin, como El Gran Dictador, Tiempos Modernos, o bien las de Jacques Tatí como Mon Oncle (Mi Tío), Las Vacaciones del Señor Hulot, y muchas otras más del cine italiano, mexicano, ese cine es estilo convertido hoy prácticamente en reliquia.

La sensación de libertad tan ansiada naturalmente por todos los seres está presente en la calidad de vida y sin duda alguna todos hemos tenido alguna vez la fantasía de poder volar como los pájaros. El rasgo principal de la sensación de libertad es la frescura y la elasticidad tanto en los movimientos cuanto en los pensamientos y su inversa es la coacción y el atenazamiento cual muro que limita así los movimientos como el pensamiento. No todos los que están detrás de los barrotes de la cárcel han perdido completamente la libertad pero tampoco, y menos aún, los que se desplazan fuera de la cárcel son seres verdaderamente "libres", porque cualquier condicionamiento va en dirección opuesta a la libertad, es decir que a mayor cantidad de imposiciones condicionantes menor libertad y por supuesto viceversa, en la medida en que las tenazas de las obligaciones y condicionamiento se reduzcan, la libertad aumenta. La libertad física siempre será limitada empezando por las necesidades elementales como lo es la de comer. Para poder comer el hombre tiene que matar y en ese sentido es una trágica condición nuestra. Estamos sujetos a la temporalidad, designio implacable del antes, el ahora y el después, y la fugacidad nos significa un condicionamiento inapelable. Sujeto está el ser humano inexorablemente a la decrepitud, la enfermedad, la vejez y la muerte. Eso lo advierte el budismo con singular claridad. Sin embargo, a propósito del budismo, en el asunto de la libertad asoma el tema de los deseos en el sentido que a mayo- res deseos, menor libertad. Cuando nos comienza a carcomer un deseo, antes de que se convierta en una necesidad, hay dos posibilidades, una es pugnar por satisfacerlo pero la otra es suprimirlo, y es obvio que la segunda opción abona en favor de la libertad y la primera al revés.

Como quiera que fuese, hablando con todo rigor, la libertad es un hecho que corresponde al espíritu si es que se entiende la libertad en su sentido de total plenitud y en consecuencia su límite, que es la iluminación, equivale a un estado de pureza y de santidad. Es ese el estado de conciencia sublime donde el ego no cuenta más porque se ha desvanecido y que los sabios hindúes llaman, en sánscrito, "jivan mukta" que se puede traducir como "liberado viviente".

Para concluir con este párrafo relacionado con la libertad citamos al psicoanalista y sociólogo Erich Fromm nacido en Alemania en el seno de una familia judía, fallecido en el 1980. Sus obras más conocidas son "El Arte de Amar" y "El Miedo a la Libertad”.

En la segunda de las citadas Fromm hace una digresión particular muy interesante con respecto a la libertad donde sostiene que el ser humano moderno y masificado tiene un temor instintivo de ejercer su libertad y prefiere endosarla a un caudillo para sentirse más seguro y evitar la responsabilidad de ser auténtico. En este sentido su análisis gira alrededor del fenómeno del nazismo que le tocó vivir.

LA FE es una virtud teologal, naturalmente consustancial a la esperanza, y es una donación del cielo que no tiene explicación lógica. Virtud (del latín virtus) quiere decir fuerza moral, poder, y la fe es un regalo precioso que disfrutan aquellos que lo han recibido y les permite vivir mucho mejor porque gozan de la auténtica confianza en que "Dios hace las cosas". La gente que goza de la po- 
tencia de la fe se encuentra en una condición tal como si estuvieran asociados con Dios y obviamente tener como socio a Dios es más ventajoso que tener como socio a Bill Gates, porque por mucho dinero que nos facilite un opulento socio capitalista la fe es una joya que no se puede adquirir ni siquiera en la mejor joyería de París.

Uno de los temas más misteriosos que se observan en la existencia humana es encontrar el porqué algunos tienen en el activo de su balance el patrimonio de la fe y otros no. La Escritura Sagrada nos enseña que "El Espíritu Sopla Donde Quiere” y no se trata en este caso de ser humanista, filósofo, sabio, Premio Nobel, brillante, doctor o profesional exitoso. La fe habitualmente es un don que proyecta el Espíritu Santo para personas humildes, iletradas, de buen corazón. Los agnósticos generalmente son personas que poseen un notable poder de razonamiento $y$ son, en ese sentido, muy inteligentes pero la razón es una facultad humana que no ocupa el primer lugar de entre las más estimables puesto que está claro que la facultad de razonamiento puro tiene muchas limitaciones. Por ejemplo, la razón fracasa cuando se pone a escudriñar asuntos propios del amor y no es capaz de explicar nada, así también pues los agnósticos declaran humildemente que se encuentran en el limbo, que no saben "si sí o si no", y de todas maneras no acceden a las ventajas inconmensurables de aquellos que tal vez no sean tan brillantes en cuestión lógica pero que en cambio cuentan con la fuerza de la fe. De donde se concluye que en la rueda de la fortuna a los que tienen fe les ha ido mejor, han tenido mejor suerte y viceversa. Evidentemente la suerte contribuye a potenciar la calidad de vida y tener fe y buena salud es de afortunados. "El Hado", según la Real Academia Española es "esa fuerza des- conocida que obra irresistiblemente sobre los dioses, los hombres y los sucesos".

Lamentablemente contar con el apoyo supremo de la fe no depende ni del cerebro ni de la voluntad, porque seguramente cualquier persona que tenga una capacidad medianamente perspicaz caerá en la cuenta de que es verdad que aquel que posee ese don está en ventaja, sin embargo, por mucho esfuerzo que hiciere, obtener ese soporte no depende de su voluntad. Es éste el misterio, por supuesto inexplicable, que marca nuestro destino. La vida está llena de contratiempos y desgracias, son inexorables e inevitables, pero el que tiene fe las puede sobrellevar con mayor ligereza, como dijo el Redentor "mi yugo es suave y mi carga ligera”. Un problema con la salud, la pérdida de un ser querido, contratiempos en el trabajo, dificultades económicas y desgracias, todos somos pasibles de sufrirlas, pero la fe, que como dijimos está asociada consustancialmente a la esperanza, es un vehículo de salvación para morigerar el dolor y por lo tanto servir de alivio en el suplicio de "este valle de lágrimas".

\section{CONCLUSIÓN}

El entorno social, el paisaje, el ambiente de trabajo, la satisfacción de las necesidades, el trabajo vocacional y creativo, el ocio productivo, la buena salud integral, el sentido del humor, la sensación de libertad, la Fe, han sido los factores que se han cotejado para ser analizados en un contexto donde sin embargo habrán de prevalecer dos que son la salud y la Fe.

Ahora bien, como fruto y resultado de una excelente calidad de vida se comprueba, en síntesis, un estado de armonía que se manifiesta en la paz interior y en la alegría de vivir siendo su exponente más claro el de la 
virtud de la generosidad que consiste en la satisfacción de dar antes que recibir.

Lo antedicho se puede resumir con un brillante texto de San Pablo en su epístola a los Gálatas, V - 22/23: "los frutos del espíritu son caridad, gozo, paz, paciencia, benignidad, bondad, longanimidad, mansedumbre, fe, modestia, continencia, castidad. Para los que viven de esta suerte no hay ley que sea contra ellos".

Es muy posible que alguien o quizá muchos, juzguen que el presente escrito está preñado o cargado con innumerables utopías en el sentido que en la práctica alcanzar los factores señalados que concurren en la calidad de vida son irrealizables. Tal vez pudieran tener razón, sin embargo lo que se sugiere es analizar serena y sinceramente si es que se ha postulado alguna afirmación falsa en el escrito, es decir que tal o cual afirmación está equivocada y por lo tanto es incorrecta.

\section{REFERENCIAS BIBLIOGRÁFICAS}

1. Epicuro Carta a Meneceo http://www. onomazein.net/4/epicuro.pdf (visitado el 04 de febrero -2011)

2. Fromm Erick, El Miedo a la Libertad. Editorial Paidos- Buenos Aires, 2005.

3. Fray Luis de León Varela. Oda a la Vida Retirada. http://users.ipfw.edu/jehle/ poesia/vidareti.htm (visitado el 04 de febrero - 2011)

4. San Pablo de Tarso. Epístola a los Gálatas Santa Biblia.

5. Taylor Frederick Winslow. Principios de la Administración Científica. Editorial El Ateneo - Buenos Aires 2006. 